\title{
The coupling of marine sulfur and iron cycle in the wake of Marinoan Snowball Earth
}

\author{
BING SHEN ${ }^{1}$, RUIMIN WANG ${ }^{1}$, BING FU ${ }^{2}$, KANGJUN \\ HUANG $^{3}$, XIANGUO LANG ${ }^{4}$
}

${ }^{1}$ Key Laboratory of Orogenic Belts and Crustal Evolution, MOE \& School of Earth and Space Sciences, Peking University, Beijing, China

${ }^{2}$ Research School of Earth Sciences, The Australian National University,Canberra ACT 0200,Australia

${ }^{3}$ State Key Laboratory of Continental Dynamics,Northwest University,Xi'an,China

${ }^{4}$ State Key Laboratory of Oil and Gas Reservoir Geology and Exploitation \& Institute of Sedimentary Geology,

Chengdu University of Technology, Chengdu, China

The terminal Cryogenian Marinoan Snowball Earth glaciation $(\sim 650-635 \mathrm{Ma})$ was immediately followed by the diversification of eukaryotes and oxygenation in the deep ocean. Previous studies proposed rapid recovery of marine primary productivity and the development of oceanic euxinia after the Marinoan glaciation. In this scenario, the dissimilatory sulfate reduction (DSR) occurred in the water column, and diffusion of $\mathrm{H}_{2} \mathrm{~S}$ from euxinic seawater into sediment porewater resulted in the syndepositional pyrite precipitation near the top of glacial deposits. This argument explained the platform-wide distributions of pyrite aggregates in the top of Nantuo Formation in South China. Pyrite formation involves with both DSR and dissimilatory iron reduction (DIR). Abundant pyrite aggregate formation also requires active DIR in sediment porewater. In this study, we analyzed sulfur $\left(\delta^{34} \mathrm{~S}_{\mathrm{py}}\right)$ and iron isotope composition $\left(\delta^{56} \mathrm{Fe}_{\mathrm{py}}\right)$ of single pyrite crystals in the topmost Nantuo Formation. Samples were collected from three sections, spanning from shelf, slope, to basin environments. Pyrites from different sections have distinct $\delta^{34} \mathrm{~S}_{\mathrm{py}}$ and $\delta^{56} \mathrm{Fe}_{\mathrm{py}}$ values. Pyrite from the slope section has the highest $\delta^{34} S_{\text {py }}$ and $\delta^{56} \mathrm{Fe}_{\mathrm{py}}$ of crustal composition, while the shelf samples have the lowest $\delta^{34} \mathrm{~S}_{\mathrm{py}}$ but the highest $\delta^{56} \mathrm{Fe}_{\mathrm{py}}$ values. We applied the two-Rayleigh distillation model to simulate the DIR and pyrite formation in sediments. The modeling results indicate the quantitative consumption of $\mathrm{Fe}^{2+}$ by pyrite formation, probably due to high seawater $\mathrm{H}_{2} \mathrm{~S}$ concentration and limited supply of organic matter for DIR, and excessive $\mathrm{Fe}^{2+}$ supply with respect to low seawater $\mathrm{H}_{2} \mathrm{~S}$ content in the shelf. Our study indicates the redox zonation in the postglacial ocean was reversed, and the marine sulfur and iron cycles were coupled by the surface ocean productivity in the aftermath of Marinoan Snowball Earth. 